\title{
Retraction Note to: Does the Time Interval Between Semen Collection, Processing and Insemination Affect Results of IUI?
}

๑) Federation of Obstetric \& Gynecological Societies of India 2019

The Editor-in-Chief has retracted this article [1] because it shows significant overlap with previously published articles [2,3].

The author has not responded to correspondence about this retraction.

[1] Allahbadia, G.N. Does the time interval between semen collection, processing \& insemination affect results of IUI? J Obstet Gynecol India Vol. 59, No. 5: September/ October 2009 pg 407-409

[2] Yavas Y, Selub MR. Intrauterine insemination (IUI) pregnancy outcome is enhanced by shorter intervals from semen collection to sperm wash, from sperm wash to IUI time, and from semen collection to IUI time. Fertil Steril 2004; 6

[3] Alexander CJ, King J, Lipari C, Zhao Y, Wallach EE. The effect of time intervals between semen collection, processing and intrauterine insemination (IUI) on pregnancy rates in clomiphene-citrate-IUI cycles. Fertil Steril 2005; Volume 84, Supplement 1, p S279

Publisher's Note Springer Nature remains neutral with regard to jurisdictional claims in published maps and institutional affiliations. 